\title{
Thoughts on the past year of Journal of Headache and Pain
}

\author{
Paolo Martelletti
}

Published online: 12 February 2008

(C) Springer-Verlag 2008

\section{Erratum to: J Headache Pain}

DOI 10.1007/s10194-008-0012-3

Owing to an error in typesetting, the HTML publication online was the uncorrected version of this editorial. The corrected version is now available.

The online version of the original article can be found under doi:10.1007/s10194-008-0012-3.

P. Martelletti $(\square)$

Department of Medical Sciences, Second School of Medicine,

Sapienza University of Rome, Via Vitorchiano 81,

00189 Rome, Italy

e-mail: paolo.martelletti@uniroma1.it 